\title{
Inteligência artificial no incremento anual de híbrido de eucalipto para desfolha e seca de ponteira
}

As técnicas de condução do povoamento de eucalipto envolvem os tratamentos silviculturais como adubação, manutenção de roço, desrama, desbaste e o manejo das pragas e doenças que atacam o povoamento, de tal maneira que as pragas e doenças florestais são responsáveis por grandes perdas no desenvolvimento dos plantios. Este estudo visa avaliar a aplicação das redes neurais artificiais na predição do efeito da desfolha e seca de ponteiro na redução da produtividade volumétrica em plantios comerciais de clone híbrido de Eucalyptus urophylla x Eucalyptus grandis na mesorregião sudeste do Pará. Os dados foram coletados em plantios comerciais de eucalipto localizados no município de Dom Eliseu, Estado do Pará. Foram treinadas 100 redes do tipo Multilayer Perceptron. Para a camada de entrada utilizou-se as variáveis qualitativas, Severidade de Desfolha e Severidade da Seca de Ponteiro (SevSec) e, a variável quantitativa Incremento Médio Anual (IMA). Na camada intermediária o número de neurônios para processamento dos dados variou entre 3 e 11 . Considerando o valor do coeficiente de correlação de Incremento Médio Anual (IMA). Na camada intermediária o número de neurônios para processamento dos dados variou entre 3 e 11 . Considerando o valor do coeficiente de correlação de Person temos indicaç̃oes diferentes das melhores redes no treinamento e na validação. A diferença entre a correlação dos valores observados do IMA7 2012 e os valores previsto para o
IMA7 2012 expressas pelo r indicam que a rede 6 foi eficiente no treinamento, no entanto não apresentou tanta eficiência na validação, sendo o valor de r no treinamento, 0,964 , enquanto na validação o segundo pior resultado, 0,933 , sendo que a rede 3 apresentou valor 0,979. Seguindo tendência diferente do $r$ e DMP (\%), a RMSE classifica a melhor rede no treinamento entre as melhores na fase de validação. A rede 6 na fase de aprendizagem mostrou valor 0,00, indicando precisão na predição dos precisa quanto a este parâmetro. A média geral dos valores estimados apresentou-se maior que a média do IMA7 2012 observado mostrando coerência à análise gráfica dos resíduos da rede 5, que possui uma leve tendência a superestimação dos resultados, porém sem significância estatística pelo teste do Qui-quadrado. As redes neurais artificiais apresentam-se como uma ferramenta com elevada precisão estatística e podem ser utilizadas na predição do efeito da desfolha e seca de ponteiro na redução da produtividade volumétrica em plantios comerciais de clone híbrido de Eucalyptus urophylla x Eucalyptus grandis na mesorregião sudeste do Pará.

\section{Artificial intelligence in the annual increment of eucalyptus hybrid for defoliation and toe drought} \begin{abstract}
The techniques for conducting eucalyptus stands involve silvicultural treatments such as fertilization, maintenance of pruning, pruning, thinning, and the management of pests and diseases
that attack the stand, so that forest pests and diseases are responsible for large losses in the development of plantations. This study evaluates the application of artificial neural networks in that attack the stand, so that forest pests and diseases are responsible for large losses in the development of plantations. This study evaluates the application of artificial neural networks in
predicting the effect of defoliation and drying of tops of trees in reducing the volumetric productivity in commercial Eucalyptus plantations urophylla x Eucalyptus grandis hybrid clone in Pará predicting the effect of defoliation and drying of tops of trees in reducing the volumetric productivity in commercial Eucalyptus plantations urophylla x Eucalyptus grandis hybrid clone in Para
southeastern mesoregion. The data were collected in commercial Eucalyptus plantations located in the Dom Eliseu, Pará State. A 100 Multilayer Perceptron networks were trained. The input layer used the qualitative variables, Defoliation Severity and Ponteiro Dryness Severity (SevSec) and the quantitative variable Average Annual Increase (IMA). In the intermediate layer the number of neurons for data processing varied between 3 and 11. Considering the value of the Person correlation coefficient we have different indications of the best nets in training and validation. The difference between the correlation of the observed values of the IMA7 2012 and the predicted values for the IMA7 2012 expressed by r indicates that net 6 was efficient in training, but did not show as much efficiency in validation, being the value of $r$ in training, 0.964 , while in validation the second worst result, 0.933 , with net 3 showing a value of 0.979 . Following a different trend than $r$ and DMP (\%), the RMSE ranks the best net at training among the best at the validation stage. Network 6 in the learning phase showed a value of 0.00, indicating a dis and networks are presented as a tool with high statistical accuracy and can be used in predicting the effect of defoliation and drying of tops of trees in reducing the volumetric productivity in commercial plantations of Eucalyptus urophylla x Eucalyptus grandis hybrid clone in the Pará southeastern mesoregion.
\end{abstract}

Keywords: Neuron; Artificial Neural Networks; Forestry.

Topic: Ciências Florestais

Reviewed anonymously in the process of blind peer

Jonas Elias Castro da Rocha (iD)

Universidade Federal Rural da Amazônia, Brasil

http://lattes.cnpq.br/2036944192394761

http://orcid.org/0000-0002-0255-087X

jonasufra@yahoo.com.br

Matheus Portela de Ataide (id

Universidade Federal Rural da Amazônia, Brasil

http://orcid.org/0000-0002-1719-5241

matheusportela999@hotmail.com

Ernandes Macedo da Cunha Neto (iD)

Universidade Federal do Paraná, Brasil

http://lattes.cnpq.br/9815192447914846

http://orcid.org/0000-0001-6775-0365

netomacedo878@gmail.com

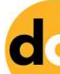

DOI: $10.6008 / C B P C 2179-6858.2021 .007 .0006$
Received: 03/07/2021

Approved: $27 / 07 / 2021$

\author{
Lina Bufalino (iD \\ Universidade Federal Rural da Amazônia, Brasil \\ http://lattes.cnpq.br/1775021506836485 \\ http://orcid.org/0000-0002-7688-3140 \\ linabufalino@yahoo.com.br \\ Cândido Ferreira de Oliveira Neto $(i b)$ \\ Universidade Federal Rural da Amazônia, Brasi \\ http://lattes.cnpq.br/0327663489224028 \\ http://orcid.org/0000-0002-6070-0549 \\ candido.neto@ufra.edu.br \\ Jade Cristynne Franco Bezerra (iD) \\ Universidade Estadual Paulista, Brasil \\ http://lattes.cnpq.br/0573058629465398 \\ http://orcid.org/0000-0001-6844-0131 \\ jadefranco9@gmail.com
}

\section{Referencing this:}

ROCHA, J. E. C.; ATAIDE, M. P.; CUNHA NETO, E. M.; BUFALINO, L.; OLIVEIRA NETO, C. F.; BEZERRA, J. C. F.. Inteligência artificial no incremento anual de híbrido de eucalipto para desfolha e seca de ponteira. Revista Ibero Americana de Ciências Ambientais, v.12, n.7, p.61-71, 2021. DOI: http://doi.org/10.6008/CBPC21796858.2021.007.0006 


\section{INTRODUÇÃO}

O Eucalyptus é um gênero originário da Austrália, onde mais de 700 espécies de eucalipto foram descobertas. A rusticidade das várias espécies de eucalipto possibilita a sua adaptação nos mais distintos sítios, evidenciando uma plasticidade fenotípica pouco comum entre outras espécies florestais (PANDOLFI, 2016). No Brasil, o eucalipto tornou-se o gênero mais abundante nos plantios comerciais do setor florestal, que segundo o a Indústria Brasileira de Árvores, corresponde a 5,6 milhões de hectares, sendo utilizada, principalmente como matéria-prima na indústria de papel e celulose, carvão vegetal e painéis de madeira (IBÁ, 2016).

A busca pela melhor expressão fenotípica motiva as indústrias a aperfeiçoarem as técnicas de implantação e condução do eucalipto, visando à obtenção da melhor produtividade nos sítios de implantação. A adoção da propagação vegetativa nos plantios comerciais de eucalipto proporcionou o estabelecimento de plantios mais produtivos, onde a expressão fenotípica das plantas é semelhante, uma vez que, o material genético das progênies é o mesmo, portanto as pequenas variações são resultado da interação entre expressão gênicas e o ambiente, que corresponde aos elementos bióticos e abióticos (NUNES, 2002).

As técnicas de condução do povoamento do eucalipto envolvem os tratamentos silviculturais como adubação, manutenção de roço, desrama, desbaste e o manejo das pragas e doenças que atacam o povoamento. As pragas e doenças florestais são responsáveis por grandes perdas no desenvolvimento dos plantios, ainda que, incidem sobre o povoamento de forma inesperada exigindo constante monitoramento pelos silvicultores (LOPES, 2011).

Os fungos compõem o rol de agentes patogênicos florestais que mais causam prejuízos nos projetos de reflorestamento, principalmente onde há condições ambientais favoráveis à sua proliferação. Dentre esses o Cylindrocladium spp. é o fungo mais se destaca nos plantios de eucalipto em todas as regiões do país, mas preferencialmente em ambientes com alta umidade e temperatura. O Cylindrocladium spp. causa manchas foliares que reduzem a área fotossintética, e consequentemente a produção dos fotoassimilados. A severidade do ataque do Cylindrocladium resultar na desfolha da planta, culminando na menor expressão do seu vigor, podendo levar a planta da morte.

A região Amazônica por dispor de um clima quente e umidade na maior parte do ano e solos ácidos que the conferem baixa capacidade de troca de cátion, tornando-os pobres no fornecimento de nutrientes à planta propicia, propicia condições edafoclimáticas favoráveis à proliferação dos Cylindrocladium spp., (DIAS, 2010). A presença do patógeno na planta causa modificações nos processos fisiológicos naturais forçando a planta a realocar fotoassimilados para suprir a carência provocada pela ação da doença. Essa realocação dos fotoassimilados compromete o crescimento da planta, o que pode acarretar perdas econômicas em um povoamento florestal comercial. O fornecimento adicional de nutrientes à planta pode minimizar os danos causados pela realocação dos fotoassimilados redirecionados para reestabelecer o seu funcionamento natural (SCHUMACHER et al., 2011). 
O efeito da desfolha e seca de ponteiro pode causar um desequilíbrio fisiológicos na planta e por conseguintemente a redação na produtividade florestal. Para tanto, torna-se necessária a mensuração do povoamento florestal, bem como o entendimento de suas taxas de crescimento, fornecendo assim, evidências da necessidade de intervenções com técnicas silviculturais para evitar perdas. Nesse sentido, o uso da Rede Neural Artificial mostra-se eficaz na predição das variáveis dendrométricas para embasamento das decisões sobre o povoamento (GORGENS et al., 2014; CUNHA NETO et al., 2018; CUNHA NETO et al., 2019a; CUNHA NETO et al., 2019b).

Desta feita, considerando que, na região amazônica são raros os trabalhos que abordam a prognose do efeito da desfolha e seca de ponteiro no incremento médio anual em volume, torna-se relevante a aplicação de uma metodologia confiável esta avaliação, de forma que a admissibilidade do êxito na adubação corretivas ou ações profilaxas podem auxiliar o gestor florestal na tomada decisões estratégicas para o empreendimento.

Neste contexto, objetivou-se avaliar a aplicação das redes neurais artificiais na predição do efeito da desfolha e seca de ponteiro na redução da produtividade volumétrica em plantios comerciais de híbridos de Eucalyptus urophylla $\times$ Eucalyptus grandis na mesorregião sudeste do Pará.

\section{MATERIAIS E MÉTODOS}

\section{Caracterização de área}

A coleta de dados ocorreu nos anos de 2011 e 2012 em áreas de plantios comerciais de híbridos de Eucalyptus urophylla x Eucalyptus grandis localizado no município de Dom Eliseu, cujas coordenadas geográficas do ponto central são 880365 W e 9539974 S, pertencente à mesorregião do Sudeste do Estado do Pará. O solo da área experimental foi classificado como Latossolo Amarelo distrófico de textura média, de acordo com o Sistema Brasileiro de Classificação de Solos (SANTOS, 2018), O clima da região é do tipo Aw, segundo a classificação de Köppen, com expressivo período de estiagem, bem como temperatura e a precipitação média anual são de 25ㅇ C e de 1638 mm, respectivamente (ÁLVARES et al., 2013).

Após observada a desfolha foi aplicada uma adubação suplementar em filete contínuo de forma mecanizada com $200 \mathrm{~kg} \cdot$ ha $^{-1}$ de NPK 08:00:32 e a lanço, 1500 kg.ha ${ }^{-1}$ de calcário dolomítico.

\section{Medição das variáveis dendrométricas}

Foram lançadas aleatoriamente e mensuradas 40 parcelas permanentes de tamanho retangular com comprimento de $24 \mathrm{~m}$ e $21 \mathrm{~m}$ de largura. Nas parcelas experimentais determinaram-se o diâmetro à altura de $1,3 \mathrm{~m}$ do solo (DAP) das árvores com mais de $4 \mathrm{~cm}$ de diâmetro ou $12,5 \mathrm{~cm}$ de circunferência à altura de $1,3 \mathrm{~m}$ do solo (CAP) pertencentes a parcela.

Para a cubagem rigorosa foram abatidas 6 árvores-amostra por estrato para cada classe de diâmetro com amplitude de 2 centímetros, sendo distribuídas em locais de alta, média e baixa produtividade. Após abater as árvores-amostra, mensuraram-se os diâmetros com casca e a espessura da casca nas posições de 
altura do solo (em metros) igual a 0,$1 ; 0,5 ; 1,0 ; 1,3 ; 2,0 ; 4,0$; e assim sucessivamente de dois em dois metros até o diâmetro com casca igual a 4,0 centímetros, sendo o volume calculado pela fórmula de Smalian e todos os compartimentos somados para obtenção do volume total da árvore. Para estimar o volume com casca até $4 \mathrm{~cm}$ do topo utilizou-se o modelo de Schumacher e Hall na sua forma original (modelo 1).

$$
\mathrm{V}_{4 \mathrm{cc}}=\beta_{0} * \mathrm{DAP}^{\beta_{1} * \mathrm{DAP}^{\beta_{2}}+\varepsilon}
$$

Onde:

$\mathrm{Ht}=$ altura total, em $\mathrm{m}$; $\mathrm{V} 4 \mathrm{cc}=$ volume com casca até $4 \mathrm{~cm}$ de diâmetro no topo do fuste, em $\mathrm{m}^{3}$; DAP = diâmetro a 1,3 metros de altura do solo, em cm; $\mathrm{Bi}=$ parâmetros do modelo a serem estimados, sendo $\mathrm{i}=0,1$ e 2; $\varepsilon=$ erro aleatório.

Para a estimava do volume aos 84 meses e, por conseguinte o incremento médio anual em volume previsto para o sétimo ano (IMA7) foi ajusta o modelo de regressão (equação 1) por meio do método dos mínimos quadrados e algoritmo Levenberg-Marquardt, com auxílio do software Statistica versão trial.

$$
\begin{gathered}
\ln (V)=\frac{\left.\left(-55,5068772088 * 4,6388578469+8,56667870787 *\left(\ln (I)^{*} \ln (S)\right)\right)^{\wedge} 1,70860388994\right)}{\left(4,6388578469+(\ln (I) * \ln (S))^{\wedge} 1,70860388994\right)} \\
\mathrm{R}^{2}=96,01(\%)
\end{gathered}
$$

Onde:

$$
V=\text { volume estimado na idade I desejada, em } \mathrm{m}^{3} / \mathrm{ha} \text {; }
$$

ln = Logaritmo neperiano;

I = idade, em meses; $\mathrm{S}=$ Índice de Sítio.

A classificação por índices de sítio constitui um método prático e consistente de avaliação da qualidade do local, pois todos os fatores de crescimento são refletidos de modo interativo no crescimento em altura, o qual está correlacionado com o crescimento em volume. No desenvolvimento das equações de índice de sítio pelo método da curva guia, o modelo que melhor se adaptou aos dados foi o Schumacher Hall (modelo 3), a saber:

$$
\operatorname{Ln}(\mathrm{Hd})=\beta_{0}+\beta_{1}\left(\frac{1}{\mathrm{I}}\right)+\varepsilon
$$

Onde: $H d=$ média das alturas dominantes por parcela, em metros; $I=$ idade, em meses; $L n=$ logaritmo neperiano; 80 e 61 = parâmetros a serem estimados; e $\varepsilon=$ erro aleatório.

\section{Delineamento experimental}

As árvores para composição do banco de dados foram selecionadas aleatoriamente de forma a amostrar todos os níveis de severidade de desfolha e severidade de seca de ponteiro, mantendo a proporcionalidade da ocorrência ambos no povoamento.

\section{Descrição das variáveis}

Os níveis de severidade tanto da desfolha quanto da seca de ponteiro foram determinados com base nos trabalhos realizados por Freitas et al. (1994) e Bertulio (2008), que conduziram os experimentos 
avaliando desfolha tanto ascendente quanto descendente e de acordo com o formato de arquitetura da copa. Os níveis de severidade de desfolha foram classificados como: baixa (+); média (++); e alta (+++) (Figura 1). Os níveis de severidade de seca de ponteiro foram classificados como: ausência (-); baixa (+); e média (++) (Figura 2). Os parâmetros dos níveis de desfolha e seca de ponteiro foram estabelecidos de acordo com a avaliação in locu.

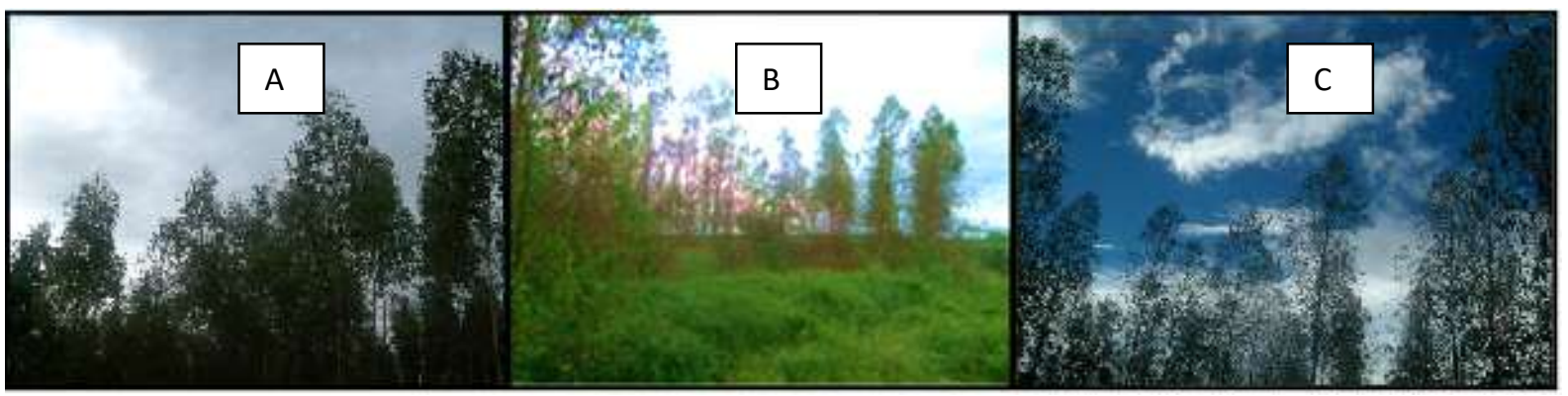

Figura 1: Desfolha no campo com intensidades: baixa (+) (A); média (++) (B); alta (+++) (C).

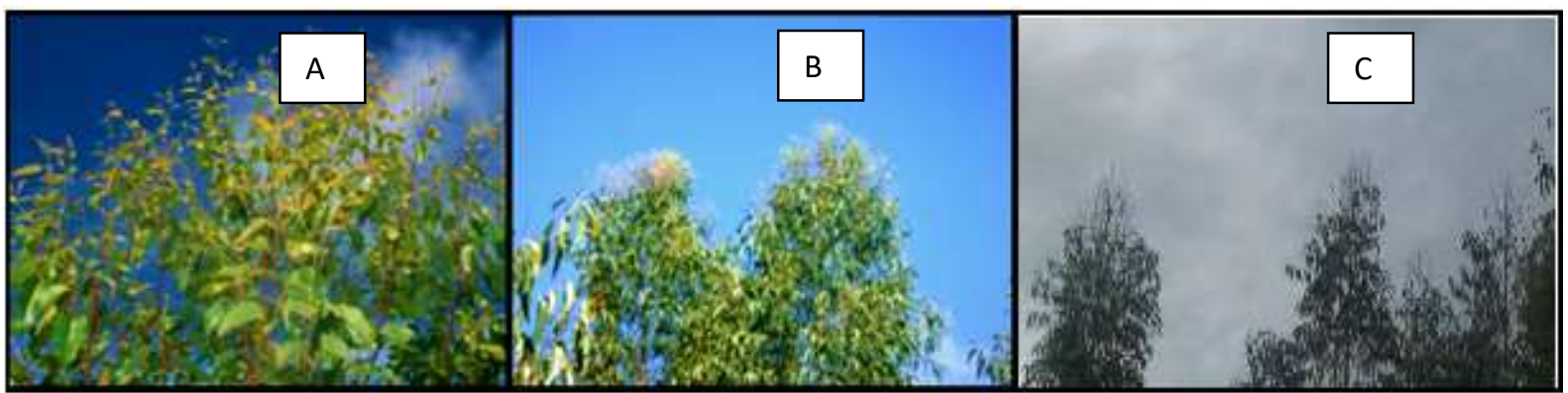

Figura 2: Seca de Ponteiro no campo com intensidades: ausente (-) (A); baixa (+); média (++) (C).

\section{Redes neurais artificiais}

As redes neurais artificiais foram treinadas por meio do algoritmo da retropropagação (backpropagation), com modo de aprendizagem supervisionado, visto que os dados fornecidos para o treinamento são indicados, para o ajuste dos pesos sinápticos.

Foram treinadas 100 redes do tipo Multilayer Perceptron, constituída por uma camada de entrada, uma camada intermediaria e uma camada de saída. Para a camada de entrada utilizou-se as variáveis qualitativas, Severidade de Desfolha (SevDesf) e Severidade da Seca de Ponteiro (SevSec) e, a variável quantitativa Incremento Médio Anual (IMA) do ano de 2011, totalizando sete neurônios nessa camada, sendo seis para variáveis qualitativas e um para variável quantitativa. Na camada intermediária o número de neurônios para processamento dos dados variou entre 3 e 11. Na camada de saída os dados expressos são o IMA7 previsto para o ano de 2012. Das 100 redes treinadas foram retidas as 10 melhores redes com base no coeficiente de correlação de Pearson ( $r$ ).

\section{Medidas de precisão do ajustamento das redes}

As redes treinadas foram avaliadas de acordo com as seguintes medidas de precisão do ajustamento: Desvio Médio Percentual (DMP), Raiz do Erro Quadrático Médio (RMSE) e Coeficiente de Correlação de Pearson ( $r)$. 
DMP: verifica a existência de tendenciosidade pela através da dispersão dos resíduos (modelo 4).

$$
\mathrm{DMP}=\frac{1}{\mathrm{n}} \cdot\left(\sum \frac{(\hat{\mathrm{y}}-\mathrm{y})}{\mathrm{y}}\right) \cdot 100
$$

Onde:

DMP = desvio médio percentual; $y=$ valor real da variável dependente; $\hat{y}=$ valor previsto da variável dependente; $\mathrm{n}=$ número de observações.

RMSE: calcula a precisão e a estabilidade das redes através da diferença quadrática média entre valores observados e previstos (modelo 5).

$$
\operatorname{RMSE}=\frac{100}{\bar{y}} \cdot \sqrt{\left(\frac{\sum_{\mathrm{i}}^{\mathrm{n}}(\hat{\mathrm{y}}-\mathrm{y})^{2}}{\mathrm{n}}\right)}
$$

RMSE = raiz do erro quadrático médio (\%); $\bar{y}=$ média dos valores observados; $\hat{y}=$ valor estimado de cada observação; $y=$ valor real de cada observação; $\mathrm{n}=$ número de observações. r: indica o grau de associação entre duas variáveis quantitativas (modelo 5).

$$
r=\frac{\sum(x-\bar{x}) \cdot(y-\bar{y})}{\sqrt{\left(\sum(x-\bar{x})^{2}\right) \cdot\left(\sum(y-\bar{y})^{2}\right)}}
$$

Onde, $r=$ coeficiente de correlação de Pearson; $\mathrm{x}=$ valor real de cada observação; $\overline{\mathrm{x}}=$ média dos valores observados; $y=$ valor estimado de cada observação; $\bar{y}=$ média dos valores estimados;

Para ordenação das melhores redes no treinamento e na validação foi considerado o Valor Ponderado (VP) das medidas de precisão do ajustamento r, DMP (\%) e RMSE. Para obtenção do VP são atribuídos pesos às medidas de precisão, sendo os pesos de 1 a 10, onde a melhor RNA recebe peso 1 , a segunda melhor RNA, peso 2 e assim sucessivamente para cada uma delas. $O$ resultado do menor somatório é atribuído à rede mais eficiente, continuando a sequência na ordem crescente (MIRANDA et al., 2015; ROCHA et al., 2015; THOMAS et al., 2006).

\section{Análise gráfica dos resíduos}

A análise gráfica dos resíduos é fundamental na determinação de um modelo, mesmo que as medias de precisão do ajustamento sejam boas indicadoras, visto que podem ocorrer erros tendenciados em algumas amplitudes de classes na variável resposta (CAMPOS et al., 2013).

Os resíduos consistem na distribuição dos valores amostrais calculado com a diferença entre o observado e o estimado do método preditivo. Para resíduos padronizados com observações excedentes a duas unidades, positivas ou negativas, considera-se outliers, uma vez que, possuem variâncias constantes iguais a um (Modelo 7).

$$
r_{p}=\frac{\hat{y}-y}{\sqrt{\frac{\sum(e-\bar{e})^{2}}{n-1}}}
$$




$$
\begin{array}{r}
\hat{y}=\text { valor estimado de cada observação; } \\
y=\text { valor real de cada observação; } \\
e=\text { diferença entre valor observado e previsto; } \\
\overline{\mathrm{e}}=\text { média da diferença entre valor observado e previsto; } \\
\mathrm{n}=\text { número de observações. }
\end{array}
$$

\section{Escolha e Validação das melhores redes neurais}

Para a escolha da melhor rede treinada foram utilizados os mesmos índices usados na avaliação, sendo: DMP, RMSE e r. A validação da rede treinada pode possibilitar sua aplicação em dados que apresentem as mesmas características das variáveis qualitativas e quantitativas descritas neste trabalho. Para a validação será aplicado o teste Qui-Quadrado ao nível de 5\% de probabilidade.

\section{RESULTADOS E DISCUSSÃO}

\begin{tabular}{|c|c|c|c|c|c|c|c|c|c|c|}
\hline \multirow{2}{*}{ RNA } & \multirow{2}{*}{ Arquitetura } & \multicolumn{4}{|c|}{ Treinamento } & \multicolumn{5}{|c|}{ Validação } \\
\hline & & $r$ & DMP (\%) & RMSE & VP & $r$ & DMP (\%) & RMSE & VP & $x^{2}$ \\
\hline 1 & MLP 7-12-1 & 0,938 & $-0,42$ & 1,19 & 23 & 0,978 & $-5,77$ & 6,31 & 20 & $1,46^{\text {ns }}$ \\
\hline 2 & MLP 7-15-1 & 0,963 & $-0,26$ & 0,79 & 11 & 0,886 & 6,96 & 3,30 & 22 & $11,68^{*}$ \\
\hline 3 & MLP 7-4-1 & 0,952 & $-0,97$ & 1,05 & 28 & 0,979 & $-5,07$ & 5,00 & 15 & $0,90^{\text {ns }}$ \\
\hline 4 & MLP 7-8-1 & 0,953 & $-0,75$ & 0,61 & 22 & 0,936 & $-4,80$ & 4,73 & 19 & $1,65^{\mathrm{ns}}$ \\
\hline 5 & MLP 7-15-1 & 0,962 & $-0,45$ & 0,49 & 14 & 0,956 & 0,10 & 1,33 & 6 & $1,88^{\text {ns }}$ \\
\hline 6 & MLP 7-8-1 & 0,964 & $-0,38$ & 0,00 & 4 & 0,933 & 8,15 & 2,88 & 20 & $21,50^{*}$ \\
\hline 7 & MLP 7-9-1 & 0,952 & $-0,42$ & 0,15 & 14 & 0,949 & $-2,37$ & 4,30 & 14 & $3,43^{\text {ns }}$ \\
\hline 8 & MLP 7-12-1 & 0,952 & $-0,43$ & 0,15 & 15 & 0,942 & $-2,23$ & 4,18 & 13 & $3,69^{\text {ns }}$ \\
\hline 9 & MLP 7-5-1 & 0,954 & $-0,68$ & 0,45 & 17 & 0,965 & $-5,64$ & 6,03 & 19 & $1,60^{\text {ns }}$ \\
\hline 10 & MLP 7-8-1 & 0,956 & $-0,48$ & 0,54 & 17 & 0,925 & $-3,47$ & 3,89 & 17 & $2,02^{\text {ns }}$ \\
\hline
\end{tabular}

As medidas de precisão do ajustamento, r, DMP (\%) e RMSE, utilizadas para avaliar as redes no treinamento e na validação, estão expressas na Tabela 1, com o valor ponderado mostrando as melhores redes.

Tabela 1: Medidas de precisão do ajustamento do treinamento e validação das redes neurais artificias.

$\mathrm{MPL}=$ Multilayer Perceptron, $r=$ coeficiente de correlação de Pearson, DMP $(\%)=$ desvio médio percentual, $\mathrm{RMSE}=$ raiz do erro quadrado médio. ${ }^{*}$ e ns = significativo e não significativo ao nível de $5 \%$ de probabilidade pelo teste $\mathrm{X}^{2}$, respectivamente.

Considerando o valor do coeficiente de correlação de Person temos indicações diferentes das melhores redes no treinamento e na validação. A diferença entre a correlação dos valores observados do IMA7 2012 e os valores previsto para o IMA7 2012 expressas pelo $r$ indicam que a rede 6 foi eficiente no treinamento, no entanto não apresentou tanta eficiência na validação, sendo o valor de $r$ no treinamento, 0,964, enquanto na validação o segundo pior resultado, 0,933, sendo que a rede 3 apresentou valor 0,979. Os resultados de $r$ de todas as redes são considerados elevados quando comparados com outros trabalhos que utilizam as RNAs como ferramenta de predição volumétrica (BINOTI et al., 2015).

No treinamento as redes tenderam a subestimar os resultados previstos mostrando DMP (\%) negativo. As redes 2 e 6 apresentaram menor tendência subestimação no treinamento, apresentando valores, $-0,26 \%$ e - $-0,38 \%$, respectivamente. Na validação a rede 5 superestimou a predição em 0,10 \%, mostrando-se a melhor rede, por este parâmetro. No entanto as redes 2 e 6 apresentaram superestimação em 6,96 \% e 8,15\%, respectivamente, na validação, classificando essas redes como as piores para predição da variável resposta. 
Seguindo tendência diferente do r e DMP (\%), a RMSE classifica a melhor rede no treinamento entre as melhores na fase de validação. A rede 6 na fase de aprendizagem mostrou valor 0,00 , indicando precisão na predição dos precisa quanto a este parâmetro. No entanto Martins et al. (2016) valida a melhor rede para afilamento do fuste pela a partir do RMSE e $r$ com a mesma tendência de classificação das melhores redes. Semelhantemente, na fase de generalização a rede 6 é a segunda mais bem classificada com valor de 2,88. As redes 1 e 3 apresentaram valor ruins tanta na fase de treinamento, com valores de 1,19 e 1,05, respectivamente, e na fase de validação, com valores de 6,31 e 5,00, respectivamente.

Binoti et al. (2015) ao utilizarem dados de área basal para projetar o volume encontrou redes com alto $r$ e baixo RMSE, indicando bons resultados no treinamento, no entanto na fase de generalização as medidas de precisão apresentaram resultados antagônicos. Uma possibilidade para que ocorra essa divergência expressiva entre a fase de treinamento e validação pode ser o sobretreinamento, ou seja, um treinamento excessivo, que consiste na memorização e não na aprendizagem na fase de treinamento, fazendo com que a função não admita padrões não esperados anteriormente. A ocorrência de sobretreinamento proporciona uma generalização ruim da rede, o que pode ter ocorrido com as redes 2 e 6 , considerando o coeficiente de correlação de Pearson e o Desvio Médio Percentual.

Ao considerar o VP para classificação das redes contemplam-se os resultados das medidas de precisão do ajustamento. Os valores ponderados atribuídos seguiram a tendência do $r$ e DMP (\%) no treinamento. O VP aponta a rede 6 como a melhor no treinamento, com valor 4. No entanto, para validação a rede 6 é classificada como a segunda pior rede para expressar a variável resposta. A rede 5, expressa o melhor VP para validação, com valor 6, seguindo a tendência do treinamento em que ela é ordenada como a terceira melhor rede, com valor 14, evidenciando o bom treinamento dessa rede. Na validação a rede 5 apresentou, em todas as medidas de precisão, classificação boa ou mediana, em relação as outras redes, culminando na sua melhor classificação para validação para predição do IMA 2012.

O teste Qui-Quadrado (Tabela 1) não apresentou diferença estatística entre os valores observados e os valores estimados para as redes $1,3,4,5,7,8,9,10$. No entanto as redes 2 e 6 apresentaram diferença estatística entre os valores previstos e observados. Assim a rede 5 pode ser utilizada como uma ferramenta estatística confiável com elevada precisão na estimativa da produtividade após ação da desfolha e seca de ponteiro em plantios de eucalipto. Na Figura 3 a análise gráfica dos resíduos mostra a superioridade da rede 5 em relação as demais quanto a dispersão total dos dados, uma vez que, a oscilação dos valores observados aproxima-se do zero dos resíduos padronizados.

Os gráficos de distribuição do resíduo apresentaram tendência à subestimação das redes para os menores valores observados, assim como Vendruscolo et al. (2015) para estimar altura em árvores de eucalipto no município de Itiquira - MT, observam tendência a subestimação dos menores valores na predição da altura de híbrido de eucalipto.

Para valores medianos todas as redes apresentaram tendência a superestimar a predição do IMA de 2012. No entanto as redes 1 , 3, 7, 8, 9 tenderam a superestimação dos maiores resultados, enquanto as redes 2, 4, 5, 6 e 10 tenderam a subestimá-los. Os resíduos não apresentaram amplitude maior que duas unidades, 
por tanto não houve outleirs, contribuindo para que as redes apresentem melhores valores na predição da variável resposta.

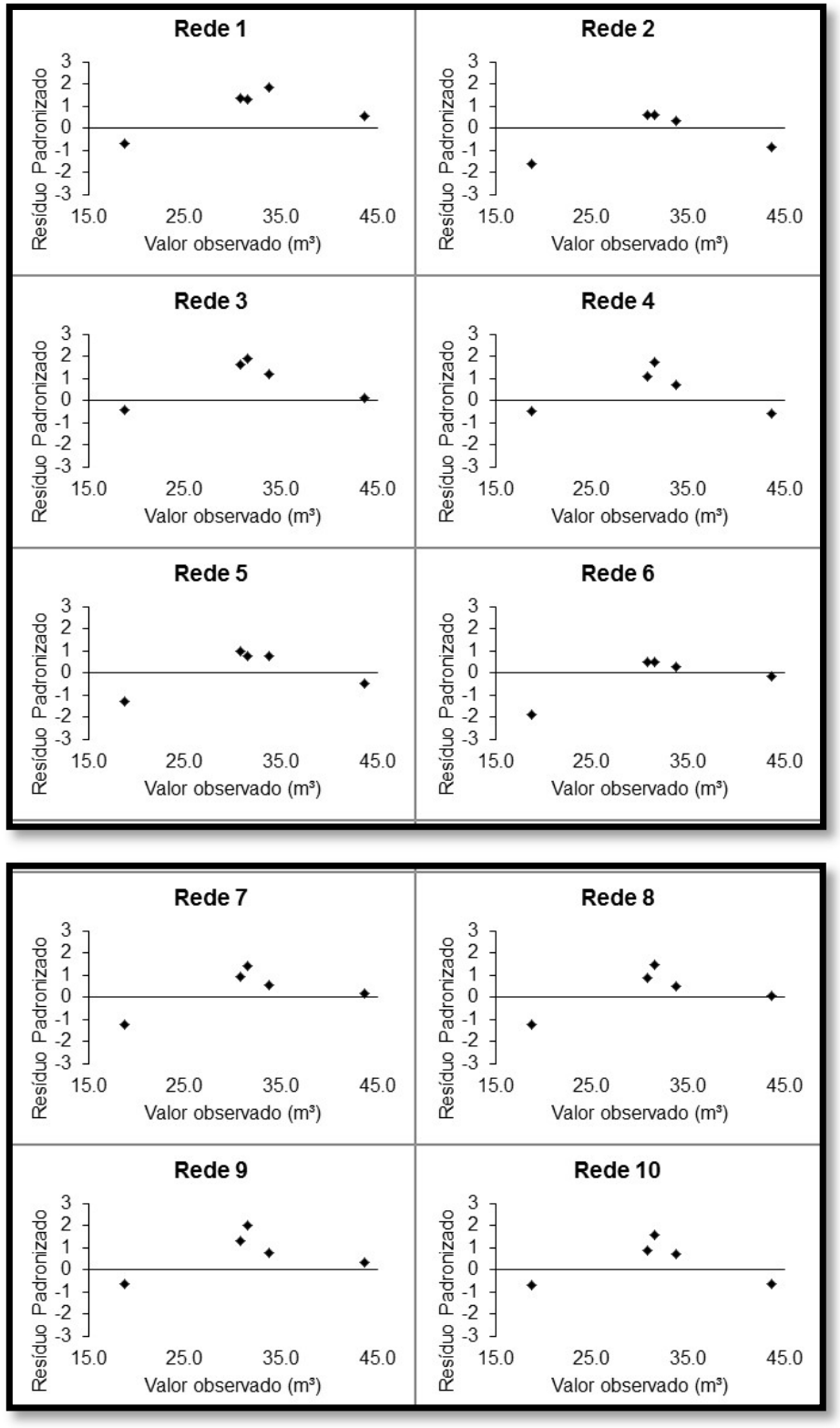

Figura 3: Gráfico de Dispersão dos Resíduos.

A rede 5 apresenta distribuição mais homogênea em relação às outras redes, corroborando com o resultado expresso pelo VP, indicando que houve adaptabilidade da rede na estimativa da variável resposta, assim como encontrado por Leal et al. (2015), quando avaliaram o uso da RNA para predição da produtividade de grãos de milho a partir de atributos do solo em Chapadão do Céu - GO. Portanto, considerando a média observada no IMA 2012 temos a média da predição da rede 5 como a mais próxima do valor real. A proximidade do resultado fornecido pela rede 5 converge com o que as medidas de precisão do ajustamento indicaram. A indicação que há recuperação fisiológica, diante da desfolha e seca de ponteiro, é evidenciada pela pequena diferença existente entre a média do IMA observado e a média da previsão feita pela rede.

A média da predição do IMA pela rede 5 por nível de desfolha e seca de ponteiro para os dados da validação pode ser observado na Tabela 2, na qual pode-se verificar a acurácia da rede na prognose. 
Tabela 2: Comparação entre a Média do IMA 2012 observado e o valor previsto pela rede 5.

\begin{tabular}{|c|c|c|c|c|}
\hline \multicolumn{5}{|c|}{ Média IMA 2012 Observado } \\
\hline \multirow{2}{*}{ Sev Desf } & \multicolumn{3}{|c|}{ Sev Sec } & \multirow{2}{*}{ Média } \\
\hline & - & + & ++ & \\
\hline+ & 18,75 & & 43,54 & 31,15 \\
\hline++ & & 31,49 & 33,76 & 32,63 \\
\hline+++ & & & 30,79 & 30,79 \\
\hline Média Geral & 18,75 & 31,49 & 36,03 & 31,67 \\
\hline \multicolumn{5}{|c|}{ Valor predito Rede 5} \\
\hline+ & 14,60 & & 41,93 & 28,27 \\
\hline++ & & 33,91 & 36,26 & 35,09 \\
\hline+++ & & & 33,94 & 33,94 \\
\hline Média Geral & 14,60 & 33,91 & 37,38 & 32,13 \\
\hline
\end{tabular}

Sev Desf= Severidade de desfolha, $(+)=$ baixa intensidade, $(++)=$ média intensidade, $(+++)=$ alta intensidade; Sev Sec $=$ Severidade da Seca de Ponteiro $(-)=$ ausente, $(+)$ baixa intensidade, $(++)=$ média intensidade.

A média geral dos valores estimados apresentou-se maior que a média do IMA7 2012 observado mostrando coerência à análise gráfica dos resíduos da rede 5 , que possui uma leve tendência a superestimação dos resultados, porém sem significância estatística pelo teste do $x^{2}$ (Tabela 2).

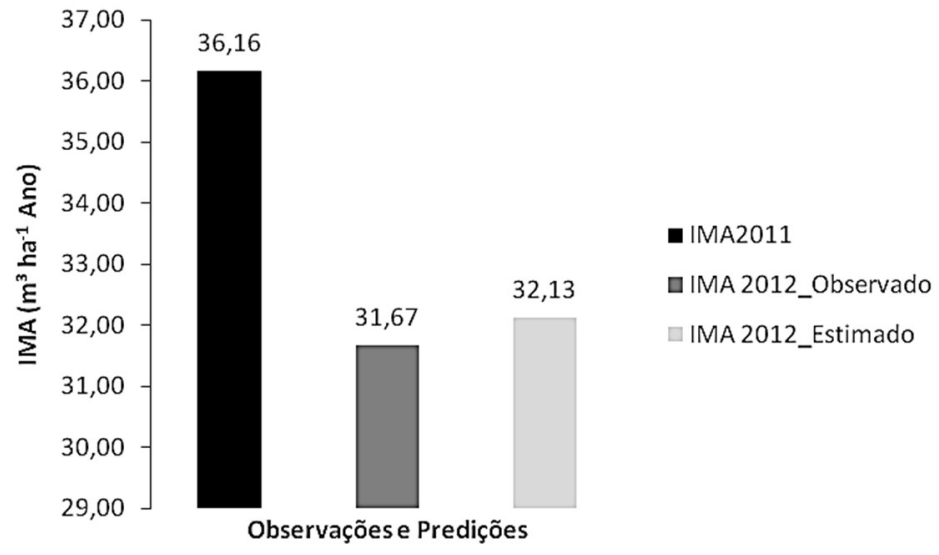

Figura 4: Médias dos IMAs observados e estimados.

A translocação de fotoassimilados para compensar o déficit de nutrientes nas vias metabólicas foi um dos efeitos negativos causados pela desfolha, reduzindo em 7, $7 \%$ a média do IMA 72012 como mostra a Figura 8. Há indicativos que a suplementação nutricional com NPK 08: 00: 32 contribuiu para redução da perda de IMA 7 para o ano de 2012, por reforçar a disponibilidade desses elementos à planta, uma vez que, o nitrogênio e o potássio adicionado pela adubação podem auxiliar na manutenção das reações bioquímicas, influenciando diretamente no desenvolvimento da planta, portanto, acredita-se que as perdas poderiam ter sido maiores. Zarpelon (2011) atesta a eficiência adubação potássica individual e interagindo com o nitrogênio tanto na redução de desfolha e no controle inóculos de Cylindrocladium.

\section{CONCLUSÕES}

As redes neurais artificiais apresentam-se como uma ferramenta com elevada precisão estatística e podem ser utilizadas na predição do efeito da desfolha e seca de ponteiro na redução da produtividade volumétrica em plantios comerciais de clone híbrido de Eucalyptus urophylla $\mathrm{x}$ Eucalyptus grandis na mesorregião sudeste do Pará. 


\section{REFERÊNCIAS}

ÁLVARES, C. A.; STAPE, J. L.; SENTELHAS, P. C.; GONÇALVES, J. L. M.; SPAROVEK, G.. Köppen's climate classification map for Brazil. Meteorologische Zeitschrift, v.22, n.6, p.711-728, 2013.

BERTULIO, V. G.. Efeitos da desfolha artificial no crescimento de plantas de Eucalyptus spp. em uma área de reflorestamento, município de campo verde, estado de mato grosso. Dissertação (Mestrado), Universidade Federal de Mato Grosso, Cuiabá, 2008.

BINOTI, M. L. M. D. S.; LEITE, H. G.; BINOTI, D. H. B.; GLERIANI, J. M.. Prognose em nível de povoamento de clones de eucalipto empregando redes neurais artificiais. 2015. Cerne, v.21, n.1, p.97-105, 2015.

CAMPOS, J. C. C.; LEITE, H. G.. Mensuração Florestal: Perguntas e Respostas. 4 ed. Viçosa: UFV, 2013.

CUNHA NETO, E. M.; BEZERRA, J. C. F.; ANDRADE, J. S.; MAR, A. L.; VAZ, M. M.; ROCHA, J. E. C.; MELO, M. R. S.; ALVES, G. A. R.. Redes neurais artificiais e regressão na estimativa da altura em povoamento experimental misto e equiâneo. Caderno De Ciências Agrárias, v.10, p.60-68, 2018.

CUNHA NETO, E. M.; BEZERRA, J. C. F.; VERAS, H. F. P.; GOUVEIA, D. M.; ARAUJO, E. C. G.; SILVA, T. C.. Estimativa Do Afilamento Do Fuste De Indivíduos De Eucalipto Por Meio De Técnicas De Inteligência Artificial. BIOFIX Scientific Journal, v.4, p.166-171, 2019a. DOI: http://doi.org/10.5380/biofix.v4i2.65831

CUNHA NETO, E. M.; BEZERRA, J. C. F.; MIRANDA, L. C.; MAR, A. L.; VAZ, M. M.; MELO, M. R. S.; ROCHA, J. E. C.. Modelo de Kozak e Redes Neurais Artificiais na Estimativa do Afilamento do Fuste de Eucalipto. Revista De Engenharia e Tecnologia, v.11, p.150-158, 2019b.

DIAS, A. C. R.. Controle químico de doenças de Eucalyptus spp. em viveiros e seus efeitos morfo-fisiológicos. Dissertação (Mestrado) - Universidade Estadual Paulista, Botucatu, 2010.

FREITAS, S.; BERTI FILHO, E.. Efeito do desfolhamento no crescimento de Eucalyptus grandis Hill ex Maiden (Myrtaceae). IPEF, n.47, p.36-43, 1994.

GORGENS, E. B.; LEITE, H. G.; GLERIANI, J. M.; SOARES, C. P. B.; CEOLIN, A.. Influência da arquitetura na estimativa de volume de árvores individuais por meio de redes neurais artificiais. Revista Árvore, v.38, n.2, p.289-295, 2014.

IBÁ. Indústria Brasileira de Árvores. Relatório Anual 2016: Banco de dados. IBÁ, 2016.

LEAL, A. J. F.; MIGUEL, E. P.; BAIO, F. H. R.; CARVALHO NEVES, D.; LEAL, U. A. S.. Redes neurais artificiais na predição da produtividade de milho e definição de sítios de manejo diferenciado por meio de atributos do solo. Bragantia, v.74, n.4, p.436-444, 2015.
LOPES, J. L. W.; SAAD, J. C. C.; GUERRINI, I. A.; LOPES, C. F. Influência dos fatores bióticos e abióticos na sobrevivência de eucalipto em função do solo e do manejo de viveiro. Biotemas, v.22, n.2, p.29-38, 2011.

MARTINS, E. R.; BINOTI, M. L. M. S.; LEITE, H. G.; BINOTI, D. H. B.; DUTRA, G. C.. Configuração de redes neurais artificiais para estimação do afilamento do fuste de árvores de eucalipto. Revista Brasileira de Ciências Agrárias, v.11, n.1, p.33-38, 2016

MIRANDA, D. L. C.; JUNIOR, V. B.; GOUVEIA, D. M.. Fator de forma e equações de volume para estimativa volumétrica de árvores em plantio de Eucalyptus urograndis. Scientia Plena, v.11, n.03, 2015

NUNES, G. D. S.; REZENDE, G. D. S. P.; RAMALHO, M. A. P.; SANTOS, J. D.. Implicações da interação genótipos $X$ ambientes na seleção de clones de eucalipto. Cerne, v.8, n.1, p.49-58, 2002.

PANDOLFI, F.. Avaliação de parâmetros de rusticidade de mudas clonais de eucalipto e suas influências no crescimento inicial do povoamento. Dissertação (Mestrado em Produção Vegetal) - Universidade Federal do Espírito Santo, Vitória, 2009.

ROCHA, M. B.; BARRETO-GARCIA, P. A. B.; PRADO, W. B.; PAULA, A.; CONCEIÇÃO JUNIOR, V.. Volumetria de Genipa americana em plantio homogêneo no Sudoeste da Bahia. Pesquisa Florestal Brasileira, Colombo, v.35, n.84, p.419425, 2015.

SANTOS, H. G.; JACOMINE, P. K. T.; ANJOS, L. H. C.; OLIVEIRA, V. A.; LUMBRERAS, J. F.; COELHO, M. R.; ALMEIDA, J. A.; ARAUJO FILHO, J. C.; OLIVEIRA, J. B.; CUNHA, T. J. F.. Sistema brasileiro de classificação de solos. Brasília: Embrapa, 2018.

SCHUMACHER, M. V.; WITSCHORECK, R. I.; CALIL, F. N.. Biomassa em povoamentos de Eucalyptus spp. de pequenas propriedades rurais em Vera Cruz, RS. Ciência Florestal, v.21, n.1, p.17-22, 2011.

THOMAS, C.; ANDRADE, C. M.; SCHNEIDER, P. R.; FINGER, C. A. G.. Comparação de equações volumétricas ajustadas com dados de cubagem e análise de tronco. Ciência Florestal, Santa Maria, v.16, n.3, p.319-327, 2006.

VENDRUSCOLO, D. G. S.; DRESCHER, R.; SOUZA, H. S.; MOURA, J. P. V. M.; MAMORÉ, F. M. D.; SIQUEIRA, T. A. S.. ESTIMATION OF Eucalyptus height by means of nonlinear regression and artificial neural networks. Revista Brasileira De Biometria, v.33, n.4, p.556-569, 2015.

ZARPELON, T. G.. Mapeamento genético da resistência e a influência da nutrição mineral na intensidade da manchade-pteridis em eucalipto. Tese (Doutorado) - Universidade Federal de Viçosa, Viçosa, 2011.

A CBPC - Companhia Brasileira de Produção Científica (CNPJ: 11.221.422/0001-03) detém os direitos materiais desta publicação. Os direitos referem-se à publicação do trabalho em qualquer parte do mundo, incluindo os direitos às renovações, expansões e disseminações da contribuição, bem como outros direitos subsidiários. Todos os trabalhos publicados eletronicamente poderão posteriormente ser publicados em coletâneas impressas sob coordenação da Sustenere Publishing, da Companhia Brasileira de Produção Científica e seus parceiros autorizados. Os (as) autores (as) posteriormente ser publicados em coletâneas impressas sob coordenação da Sustenere Publishing, da Companhia Brasileira de Produção Cientifica e seus pã 